\title{
SYNTHESIS, CHARACTERISATION AND CATALYTIC STUDIES OF NANO ZINC OXIDE-ALUMINA FOR DISPLACEMENT REACTION ON CARBONYLDIIMIDAZOLE
}

\author{
S. Sumathi ${ }^{1, *}$, M. Balaganesh ${ }^{1}$ and K.K. Balasubramanian ${ }^{2}$ \\ ${ }^{1}$ Department of Chemistry, Hindustan Institute of Technology and Science, Chennai, India \\ ${ }^{2}$ Department of Biotechnology, Indian Institute of Technology Madras, Chennai, India \\ *E-mail: sumathi@hindustanuniv.ac.in
}

\begin{abstract}
Nano zinc oxide supported on alumina was prepared by chemical method and calcined at $300{ }^{\circ} \mathrm{C}$. The calcined material was characterized by UV-Visible spectroscopy, Infra-Red spectroscopy, X-Ray Diffraction technique, Scanning Electron Microscopy, Thermogravimetric analysis and Porosimetry. The catalytic activity studies on alumina supported zinc oxide for the synthesis of disubstituted ureas through displacement reaction on carbonyldiimidazole are hitherto unreported. Thus, alumina supported nano zinc oxide was tested for its catalytic activity in the displacement reaction of carbonyldiimidazole with cyclohexylamine. While, the above reaction when carried out at room temperature, afforded 1,3-Dicyclohexyl urea, as the sole product in $88 \%$ yield in 20 hours, at $80{ }^{\circ} \mathrm{C}, 1,3$-dicyclohexyl urea was obtained in $80 \%$ yield, in 4 hours. Reusable and safer catalysts, reaction at room temperature, simple workup and product with good yield and purity are the merits of this process.
\end{abstract}

Keywords: Nano zinc oxide, alumina, SEM, XRD, carbonyldiimidazole, amines, disubstituted ureas.

(C) RASĀYAN. All rights reserved

\section{INTRODUCTION}

Catalysts that promote reactions with remarkable regioselectivity, higher yield, shorter reaction time and significant turn-over number are ideal for their extensive utility in synthetic organic chemistry. Nano zinc oxide, one such catalyst fulfills the above requirements and the following few examples illustrate its applications in organic reactions. Catalytic conversion of isobutanol at $250{ }^{\circ} \mathrm{C}-400{ }^{\circ} \mathrm{C}$ over zinc oxide resulted in higher selectivity of dehydrogenation over dehydration. ${ }^{1}$ Good stability of $\mathrm{ZnO}$ under highly acidic conditions, makes it more suitable in the three-component condensation, involving an aldehyde, $\beta$ keto ester and urea (Biginelli reaction). ${ }^{2}$ In the Hantzsch condensation, it is reported that lesser reaction time and higher yield is more pronounced, with $\mathrm{ZnO}$ nanoparticles. ${ }^{3}$ Thus, nano zinc oxide, being a more effective catalyst, is employed in new C-C, C-P, C-N, C-S bond formations via Michael addition reaction ${ }^{4}$, in synthesis of organic carbonates ${ }^{5}$, in Friedel-Crafts acylation ${ }^{6-8}$ for the synthesis of aromatic ketones, in reaction of acid chlorides with alcohols /thiols / phenols ${ }^{9}$, Friedlander Quinolone synthesis ${ }^{10}$, etc. Nano $\mathrm{ZnO}$ has also been employed under solvent-free conditions in reactions in which, a higher yield $(90-98 \%)$ has been achieved. ${ }^{11-12}$ These partly accounts for the associated developments in the synthesis of nano $\mathrm{ZnO} .{ }^{13-16} \mathrm{Still}$, not much has been reported on the use of $\mathrm{ZnO} \mathrm{NP}$ in bulk or as $\mathrm{ZnO} \mathrm{NP}$ on a suitable support, for the synthesis of substituted ureas. Symmetrical dicyclohexyl urea is a potent soluble epoxide hydrolase ( $\mathrm{sEH}$ ) inhibitor and known to lower systemic blood pressure. ${ }^{17}$ Also, cyclohexyl urea derivatives are known to exhibit antioxidant and antimicrobial activities. ${ }^{18}$ The available synthetic methods for substituted ureas mostly involve expensive catalysts such as $\mathrm{Pd}, \mathrm{Ru}, \mathrm{Rh}$ etc ${ }^{19-20}$ and hazardous reagents such as azides ${ }^{21}$, isocyanates. ${ }^{22-23}$ Due to a limited number of cost-effective and ecofriendly methods ${ }^{24-28}$ and extensive application of urea derivatives ${ }^{29}$, especially in pharmaceutical ${ }^{30}$ and agricultural fields ${ }^{31-37}$, continuous attention exists among the synthetic organic chemists towards developing effective methods for their synthesis.

The successful synthesis of unsymmetrical tetrasubstituted ureas, reported earlier from our laboratory involve the reaction of carbonyldiimidazole (CDI) with various types of amines, in presence of Rasayan J. Chem., 13(1), 548-555(2020)

http://dx.doi.org/10.31788/RJC.2020.1315487

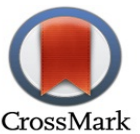




\section{RASĀYAN J. Chem. \\ Vol. 13 | No. 1 |548 - 555| January - March | 2020}

trimethylaluminium $\left(\mathrm{AlMe}_{3}\right){ }^{38}$ This reaction, applicable to a large number of substrates, led to desired products in good yields and exhibited a good functional group tolerance. But a longer reaction time and a higher temperature associated with the pyrophoric nature of the catalyst made us search for a safe and alternative catalyst. ZnO being non-toxic, non-pyrophoric, safer to handle and versatile, it was thought that $\mathrm{ZnO} \mathrm{NP}$ could serve as a substitute for $\mathrm{AlMe}_{3}$. Choosing alumina as the inert support, we synthesized $\mathrm{ZnO}$ on alumina by chemical method, characterized and studied its catalytic activity for the synthesis of dicyclohexyl urea through displacement reaction on CDI with cyclohexylamine. To the best of our knowledge, this is the first report on the synthesis of disubstituted urea using zinc oxide as a catalyst.

\section{EXPERIMENTAL}

All the chemicals, solvents and reagents used in this study were of laboratory grade/synthesis grade and used without any purification unless otherwise required. Characterization of $\mathrm{ZnO}$ on alumina was done by Thermogravimetry Analysis (TGA), Porosimeter, Scanning Electron Microscopy (SEM), X-Ray Diffraction (XRD), Infrared (IR) and Ultraviolet-Visible (UV) spectrophotometry techniques. Thermogravimetry was done on a Q500 Hi-Res TGA unit equipped with a vertical furnace where a temperature ranges of $50{ }^{\circ} \mathrm{C}-900{ }^{\circ} \mathrm{C}$ and a heating rate of $20{ }^{\circ} \mathrm{C} / \mathrm{min}$ was employed. Here, sample purge gas used was high pure nitrogen. Micromeritics ASAP 2020 porosimeter was used to determine the BET surface area. Bruker D8 Advance Powder X-Ray Diffractometer was used for the XRD studies. The phase evolution of calcined powder was studied by using $\mathrm{Cu} \mathrm{K} \alpha$ radiation target at $40 \mathrm{kV}$ and $30 \mathrm{~mA}$ and a with a scan rate of $10^{\circ} / \mathrm{min}$. The data on $2 \theta$ was recorded in the range $10-90^{\circ}$. Jeol JSM-6390 Scanning Electron Microscope was used to characterize the mean particle size and morphology of the nanoparticles. The accelerating voltage of the microscope was kept in $20 \mathrm{kV}$. The optical absorption spectrum of zinc oxide nanoparticles was recorded using JASCO (V-350) Double Beam UV Visible Spectrophotometer at a scan speed of $400 \mathrm{~nm} / \mathrm{min}$. The spectral bandwidth of Spectrophotometer was $5 \mathrm{~nm}$ and the scanning in the wavelength range of 200 to $900 \mathrm{~nm}$ was done with a data interval of $1 \mathrm{~nm}$.

Progress of the reactions was monitored by using Thin Layer Chromatography using Aluminum backed, silica gel TLC plate coated with fluorescent indicator $F_{254}$. Ethyl acetate and n-hexane mixture $(3: 2)$ was used as the eluent. Melting points reported for the crude products are uncorrected. The ${ }^{1} \mathrm{H}$ NMR and ${ }^{13} \mathrm{C}$ NMR spectra were recorded on a Jeol FX200 spectrometer using TMS as internal standard and DMSOD6 as a solvent. FT IR of the sample as $\mathrm{KBr}$ pellet was recorded on JASCO FT/IR-410 infra-red spectrometer.

\section{Synthesis of Zinc oxide-Alumina}

\section{RESULTS AND DISCUSSION}

The catalyst, zinc oxide-alumina was prepared by precipitation method as described below. In a $2 \mathrm{~L}$ beaker, $7.52 \mathrm{~g}$ of neutral alumina and $6.63 \mathrm{~g}$ of zinc acetate dihydrate were placed and $800 \mathrm{~mL}$ of water was added. This mixture was stirred well using a mechanical stirrer. $2.65 \mathrm{~g}$ of sodium hydroxide was dissolved in $100 \mathrm{~mL}$ of water. To the mixture containing zinc acetate and alumina, under stirring, the sodium hydroxide solution was added slowly over 80 minutes. The reaction mass appeared as a milky white suspension. After the complete addition of the sodium hydroxide solution, the contents were heated over a water bath kept at $90{ }^{\circ} \mathrm{C}$, for two hours. A white precipitate formed was allowed to settle (30 minutes). Decantation of the supernatant liquid and subsequent filtration under vacuum, afforded zinc oxide-alumina as a white solid mass. This was washed with ethanol $(2 * 25 \mathrm{~mL})$ followed by water $(2 * 25$ $\mathrm{mL}$ ) and then dried at room temperature for two hours. Further drying was done in a hot-air oven maintained at $120{ }^{\circ} \mathrm{C}$ for two hours. Then, calcination was done at $300{ }^{\circ} \mathrm{C}$ for three hours in a muffle furnace. This calcined zinc oxide-alumina obtained as a white powder $(8.58 \mathrm{~g}, 86 \%$ yield $)$ was characterized and their details are given below.

\section{Characterization of Zinc oxide-Alumina}

The SEM images of $\mathrm{ZnO}-\mathrm{Al}_{2} \mathrm{O}_{3}$ sample (Fig.-1) showed rod-shaped particles with an average particle size of approximately $50 \mathrm{~nm}$. The support material, alumina is not visualized in the SEM picture and this may probably be due to the amorphous nature of the support. 
RASĀYAN J. Chem.

Vol. 13 | No. 1 |548 - 555| January - March | 2020

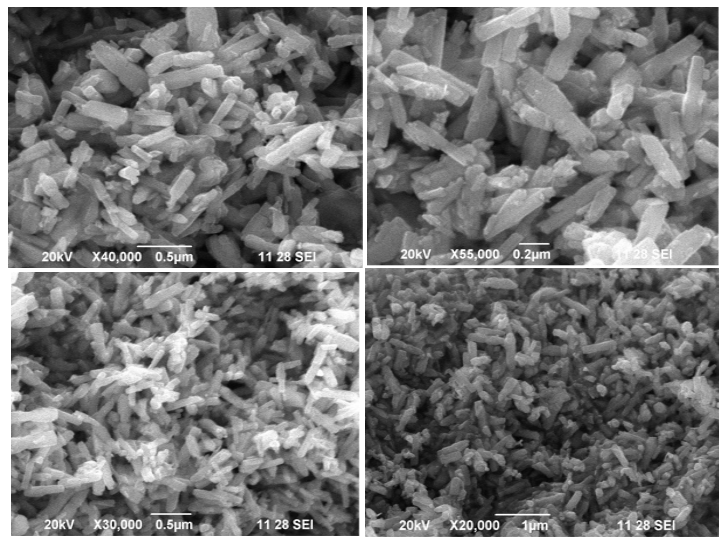

Fig.-1: SEM: ZnO NP supported on $\mathrm{Al}_{2} \mathrm{O}_{3}$

The crystallinity of the synthesized $\mathrm{ZnO} \mathrm{NP}$ is reflected by the peaks with well-defined shape in X-Ray Diffraction Spectrum (XRD) (Fig.-2). The peaks corresponding to $2 \theta$ values of the sample, resemble $\mathrm{ZnO}$ wurtzite structure (JCPDS Data Card No: 36-1451) and the purity of the sample is good, as evidenced by the absence of peaks other than that of $\mathrm{ZnO} .{ }^{39}$ Here again, diffraction peaks, characteristic of alumina were not seen. It is important to mention here that alumina doped zinc oxide synthesized elsewhere by coprecipitation technique or by hydrothermal route, exhibited relatively broad peaks corresponding to zinc oxide with low intensity ${ }^{40-41}$. The nanoparticles crystallite sizes calculated from Xray line broadening using Debye-Scherrer equation for the strongest three peaks at $2 \theta 32.0,34.67$ and 36.5 were about $26.28 \mathrm{~nm}, 26.63 \mathrm{~nm}$ and $30.06 \mathrm{~nm}$ respectively.

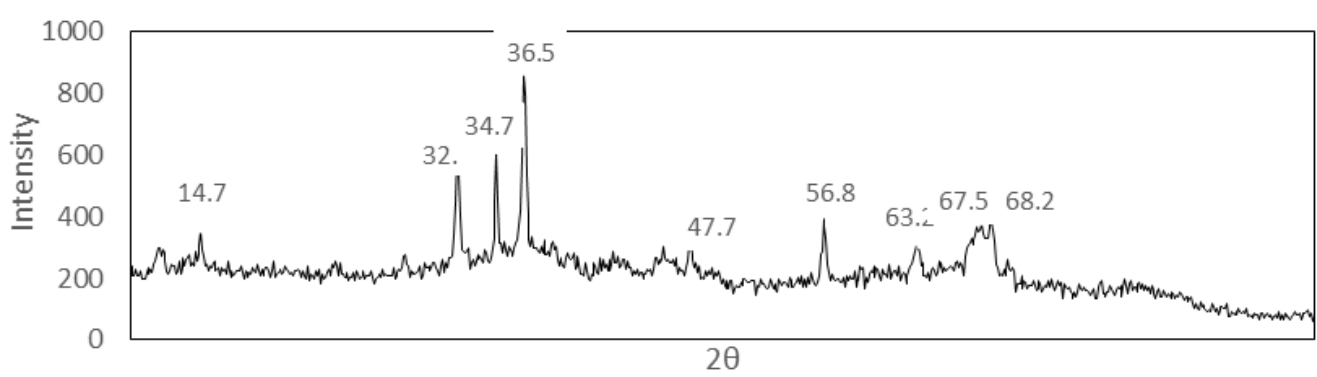

Fig.-2: XRD Spectrum of $\mathrm{ZnO}-\mathrm{Al}_{2} \mathrm{O}_{3}$

UV-DRS spectrum of $\mathrm{ZnO}-\mathrm{Al}_{2} \mathrm{O}_{3} \mathrm{NP}$ in Fig.-3 reveals the absorbance peak in the range of $350-380 \mathrm{~nm}$ corresponding to the characteristic band of $\mathrm{ZnO} \mathrm{NP} \mathrm{P}^{42}$. This is also in accordance with the reports available in the literature on the UV spectral characteristics of $\mathrm{ZnO} \mathrm{NP} .^{43-45}$

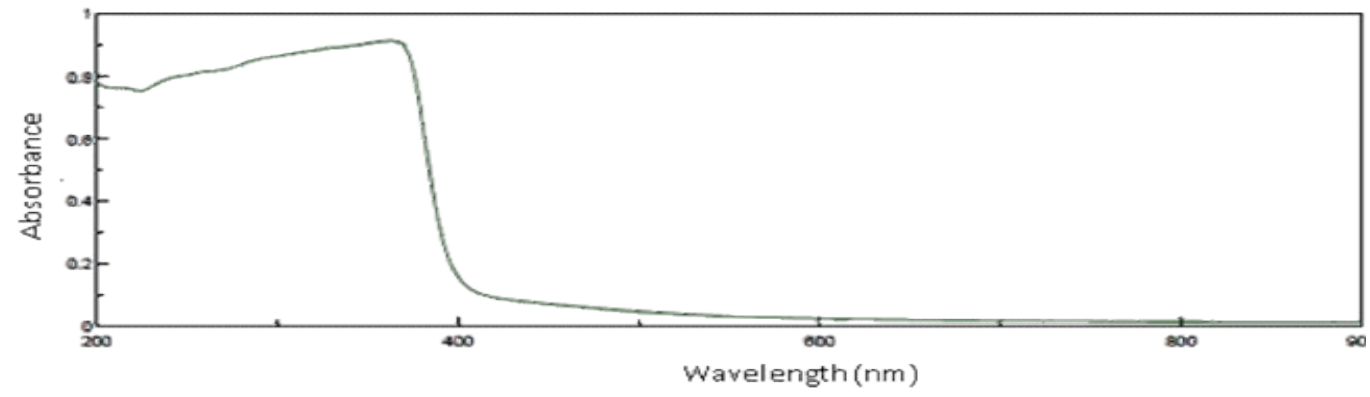

Fig.-3: UV-Vis Spectra of $\mathrm{ZnO}-\mathrm{Al}_{2} \mathrm{O}_{3} \mathrm{NP}$

Whereas aluminium doped $\mathrm{ZnO} \mathrm{NP}$ has been reported to exhibit a blue shift in the UV absorption attributed to the direct transition of electrons in the $\mathrm{ZnO}$ nanocrystals. The absence of such observation in UV absorption may probably due to the insignificant structural influence of $\mathrm{Al}_{2} \mathrm{O}_{3}$ on $\mathrm{ZnO}$ in the present 
RASĀYAN J. Chem.

Vol. 13 | No. 1 |548 - 555| January - March | 2020

study. In FTIR spectrum of the $\mathrm{ZnO}-\mathrm{Al}_{2} \mathrm{O}_{3} \mathrm{NP}$, the peak at $543 \mathrm{~cm}^{-1}$ corresponds to the characteristic absorption of $\mathrm{Zn}-\mathrm{O}$ bond and the broad absorption peak at $3398 \mathrm{~cm}^{-1}$ and a peak at $2363 \mathrm{~cm}^{-1}$ is attributed to hydroxyl and $\mathrm{C}=\mathrm{O}$ groups, probably due to moisture and carbon dioxide respectively. ${ }^{46-47}$

In thermogravimetric analysis (TGA), when $\mathrm{ZnO}-\mathrm{Al}_{2} \mathrm{O}_{3} \mathrm{NP}$ was heated from room temperature to $900{ }^{\circ} \mathrm{C}$ under nitrogen atmosphere, a significant weight loss $(6.34 \%)$ was observed in the range of $30{ }^{\circ} \mathrm{C}-300{ }^{\circ} \mathrm{C}$ (Fig.-4). Further weight loss in the wide range of $300{ }^{\circ} \mathrm{C}-900{ }^{\circ} \mathrm{C}$ was about $4.06 \%$. In the TGA of the sample, a peak was observed between $90{ }^{\circ} \mathrm{C}-150^{\circ} \mathrm{C}$ and this may be due to loss of absorbed water and another peak observed around $330^{\circ} \mathrm{C}$ may be attributed to the oxidation of organic materials. In effect, there was an overall steady decrease in weight loss with an increase in the temperature. ${ }^{48}$ Porosimetry studies done for the $\mathrm{ZnO}-\mathrm{Al}_{2} \mathrm{O}_{3} \mathrm{NP}$ revealed a BET surface area of $74.1369 \mathrm{~m} / \mathrm{g}$. The average pore volume of pores less than $190 \mathrm{~nm}\left(\mathrm{P} / \mathrm{P}_{\mathrm{o}}=0.9897\right)$ was $0.1676 \mathrm{~cm}^{3} / \mathrm{g}$ and the pore size was found to be $52.601 \AA$.

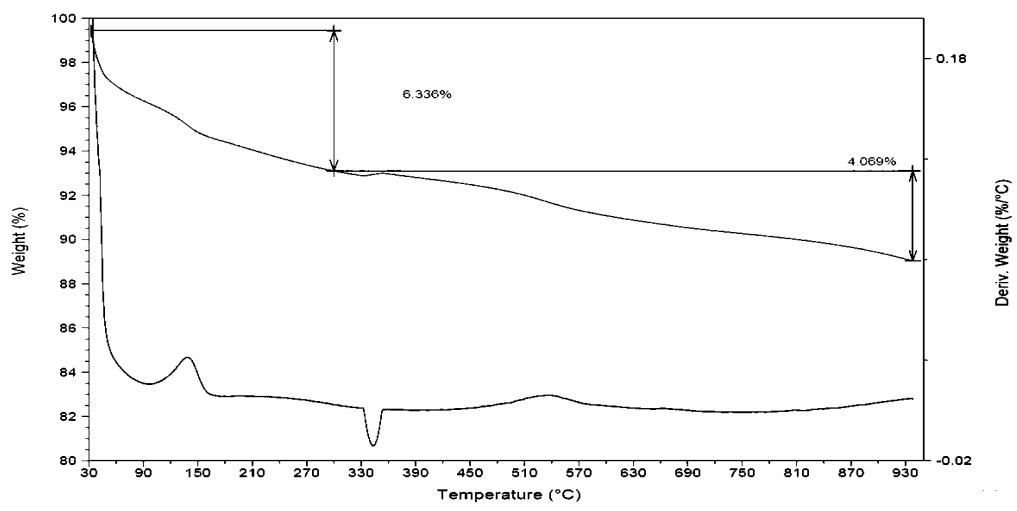

Fig.-4 Thermogravimetric Analysis of $\mathrm{ZnO}-\mathrm{Al}_{2} \mathrm{O}_{3} \mathrm{NP}$

\section{Catalytic Activity of $\mathrm{ZnO}-\mathrm{Al}_{2} \mathrm{O}_{3} \mathrm{NP}$ in Displacement Reaction on CDI}

The synthetic utility and catalytic activity of the prepared $\mathrm{ZnO}-\mathrm{Al}_{2} \mathrm{O}_{3} \mathrm{NP}$ were assessed by displacement reaction on CDI (water-soluble) with cyclohexylamine as follows. A solution of CDI (1 equiv.) and cyclohexylamine (1 equiv.) in $20 \mathrm{~mL}$ toluene, kept at room temperature for 144 hours, afforded the expected product symmetrical dicyclohexyl urea (DCU) in negligible quantity. Reactants mixed with 0.05 equivalents of neutral $\mathrm{Al}_{2} \mathrm{O}_{3}$ and stirred at room temperature for 14 hours did not lead to any reaction. The poor reaction in the absence of $\mathrm{ZnO}$ signifies that there is an interaction of the catalyst species $\mathrm{ZnO}$, with the substrate, $\mathrm{CDI}$, thereby enhancing the nucleophilic attack at the carbonyl center.

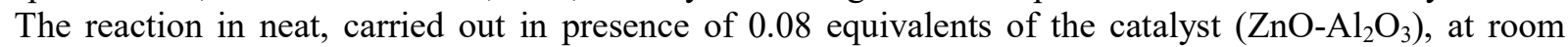
temperature for 14 hours, under unstirred conditions, afforded the product, DCU in $1.78 \%$ yield. As the support material is in the amorphous state, diffusion of the reactants through the solid surface containing the active species, $\mathrm{ZnO}$ is difficult and this might delay the formation of CDI-catalyst complex and hence, a poor yield.

The successful synthesis of DCU catalyzed by $\mathrm{ZnO}-\mathrm{Al}_{2} \mathrm{O}_{3}$ is described below. To CDI ( 1 equiv.) taken in $20 \mathrm{~mL}$ toluene, $\mathrm{CHA}$ ( 2 equiv.) and $\mathrm{ZnO}^{-\mathrm{Al}_{2} \mathrm{O}_{3}}$ (0.08 equiv.) were added and then stirred at room temperature for 14 hours. Thin Layer Chromatographic analysis (3:2 EtOAc-n-hexane) of the reaction mixture after 14 hours, indicated the presence of $C D I\left(R_{f}=0.175\right)$, a new spot at $R_{f}=0.075$, but the spot corresponding to cyclohexylamine $\left(\mathrm{R}_{\mathrm{f}}=0.375\right)$ was not seen (Scheme-1).

Toluene was removed from the reaction mixture by filtration and the solid mass was washed with water and filtered. The solid product mass containing the catalyst was extracted with methylene dichloride (10 $\mathrm{mL}$ ) and filtered to separate the catalyst. The catalyst was washed with $2 \mathrm{~mL}$ methylene dichloride followed by $10 \mathrm{~mL}$ of water, then dried in a hot air oven at $110{ }^{\circ} \mathrm{C}$ for 2 hours and labelled as recovered catalyst. The organic layer was dried over anhydrous sodium sulphate. Removal of the solvent afforded a white solid mass. It was dried at room temperature for 1 hour and then dried at $100{ }^{\circ} \mathrm{C}$ for 3 hours $(74.4 \%$ yield, Scheme-1). This product melted at $230{ }^{\circ} \mathrm{C}$ (Lit. M.P. of 1,3-Dicyclohexyl urea $=229{ }^{\circ} \mathrm{C}-230{ }^{\circ} \mathrm{C}^{47}$. 
RASĀYAN J. Chem.

Vol. 13 | No. 1 |548 - 555| January - March | 2020

TLC of this isolated crude product showed a single spot with $\mathrm{R}_{\mathrm{f}}=0.075$. The ${ }^{1} \mathrm{H}$ NMR spectrum of the product indicated the characteristic proton signals (-NCH at $3.4 \mathrm{ppm} ;-\mathrm{N} \underline{\mathrm{H}} 5.4 \mathrm{ppm})$. The ${ }^{13} \mathrm{C} \mathrm{NMR}$ spectrum showed urea carbonyl (-N-CO-N-) at $157 \mathrm{ppm}$ and $-\mathrm{N} \underline{\mathrm{CH}}$ at $34 \mathrm{ppm}$. The IR spectrum indicated the presence of peaks due to $-\mathrm{NH}$ in the region of $3250 \mathrm{~cm}^{-1}-3600 \mathrm{~cm}^{-1}$ as well as due to urea carbonyl.

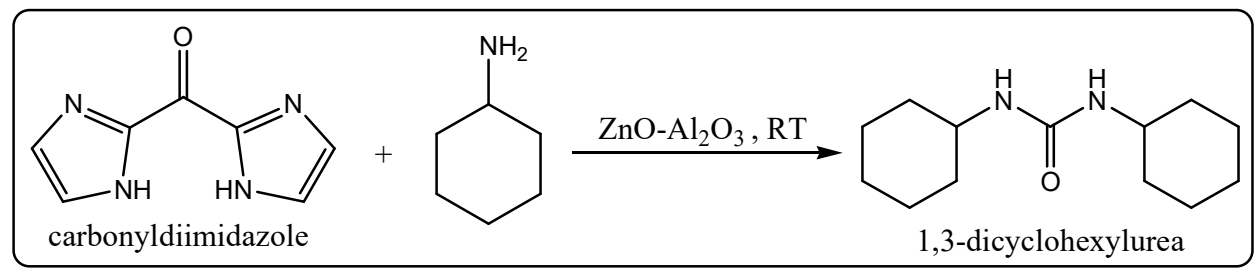

Scheme-1: $\mathrm{ZnO}-\mathrm{Al}_{2} \mathrm{O}_{3}$ Catalyzed Synthesis of Dicyclohexyl Urea

It is to be noted that in the above reaction, either the use of four equivalents of cyclohexyl amine or performing the reaction under closed conditions has no significant influence on the yield of DCU. A mixture of CDI (1 equiv.), cyclohexylamine (1 equiv.) and 0.03 equivalents of the $\mathrm{ZnO}$ (bulk) in $20 \mathrm{~mL}$ toluene, when stirred for 14 hours led to the product DCU in $67.4 \%$ yield. The optimum reaction time for maximum yield of the product in the $\mathrm{ZnO} / \mathrm{Al}_{2} \mathrm{O}_{3}$ catalyzed reaction is 20 hours (Fig.-5). Increase in reaction time from 20 hours to 28 hours, though resulted in complete consumption of starting material (by TLC), it has not led to significant improvement in the yield. Decomposition of the reactants or loss of catalytic activity due to slow poisoning during the longer reaction time, either by cyclohexylamine or by the product may account for the observed loss in reaction yield. Also, no significant change in the yield was observed, even with a two-fold increase in the quantity of the catalyst (Fig.-6).

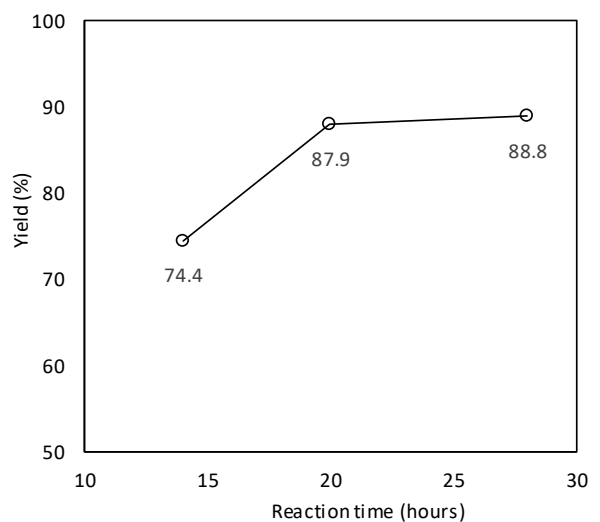

Fig.-5: Influence of Reaction Time

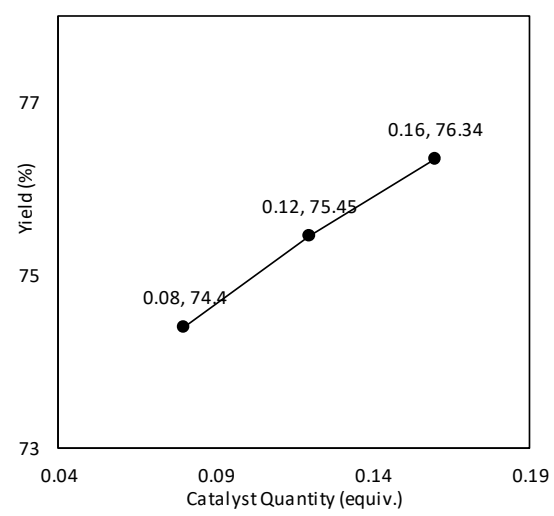

Fig.-6: Influence of Catalyst Quantity

This may be due to the blocking of the active sites caused by the strong adsorption of the product and the amorphous nature of the support that results in a reduced diffusion rate. In the studies on the effect of solvent on the reaction yield (Table-1), it is inferred that polar solvents led to a lower yield of the product. Among the solvents employed, the preferred solvent is toluene, where the reaction yield (74.4\%) was the highest in 14 hours. Reduction in yield of the product by $10 \%-15 \%$ was observed when the recovered catalyst was reused.

It is significant to mention here that in synthesis involving condensation of S, S-dimethyl dithiocarbonate reagent with cyclohexylamine, the reaction occurred at $65^{\circ} \mathrm{C}$ and DCU was obtained in $65 \%$ yield ${ }^{49}$ and it yet another report, DCU was prepared in good yield from urea and cyclohexane but multiple devices are required and the reaction requires a temperature as high as $180{ }^{\circ} \mathrm{C}^{50}$. In the present study, while the

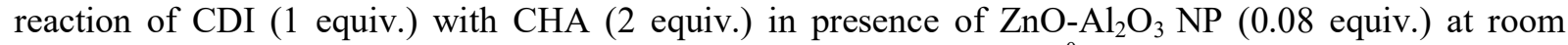
temperature for 14 hours afforded DCU in $74.4 \%$ yield, reaction at $50{ }^{\circ} \mathrm{C}$ resulted in an increase in yield $(81.25 \%)$ associated with a decrease in reaction time ( 8 hours). Under the conditions of reflux, though the 
RASĀYAN J. Chem.

Vol. 13 | No. 1 |548 - 555| January - March | 2020

reaction got completed in 4 hours, the yield has not improved (80\%). A $20 \%$ loss in yield could be attributed to the decomposition of the starting materials or products under the reaction conditions.

Table-1: Influence of Solvent on Reaction Yield

\begin{tabular}{c|l|c}
\hline S. No. & \multicolumn{1}{|c}{ Solvent } & Yield (\%) \\
\hline 1 & Water & 24.10 \\
\hline 2 & Acetone & 32.14 \\
\hline 3 & Dioxane & 41.07 \\
\hline 4 & THF & 42.85 \\
\hline 5 & Ethyl acetate & 45.09 \\
\hline 6 & EDC / MDC & 51.79 \\
\hline 7 & Acetonitrile & 54.91 \\
\hline 8 & Cyclohexane & 66.52 \\
\hline 9 & Toluene & 74.40 \\
\hline 10 & Neat, solvent-free & 38.84 \\
\hline $\begin{array}{r}\text { Reaction conditions: CHA (2 equiv.) } \\
\text { ZnO-Al } \text { O }_{3} \text { (0.08 equiv.), } 14 \text { hours, } \text { room temperature }\end{array}$
\end{tabular}

\section{CONCLUSION}

Zinc oxide-alumina, synthesized by the chemical method was characterized by UV-Visible, IR, TGA, $\mathrm{XRD}$, SEM and porosimetry. The support material appeared to be non-crystalline and $\mathrm{ZnO} \mathrm{NP}$ synthesized corresponds to Wurtzite structure and the pore size of the NP was $50 \mathrm{~nm}$. The catalyst is active and is highly useful for the synthesis of 1,3-dicyclohexyl urea. The reaction at room temperature involving a cheap and safe catalyst, simple workup and crude product with reasonable purity are the merits of this synthesis. The optimum and mild conditions that can be employed for maximum yield of the product, dicyclohexyl urea $(88.8 \%)$, corresponds to the reaction of CDI (1 equiv.) with CHA (2 equiv.) under stirring in toluene as solvent, at room temperature for 20 hours.

\section{ACKNOWLEDGMENT}

The financial help and moral support received from Hindustan Institute of Technology and Science, is duly acknowledged. Department of Chemistry and SAIF, IIT Madras, Chennai is gratefully acknowledged for the characterization of the samples.

\section{REFERENCES}

1. L. Saad, M. Riad, Journal of Serbian Chemical Society, 73, 997(2008), DOI: $10.2298 /$ JSC0810997S

2. K. Bahrami, M.M. Khodaei, A. Farrokhi, Synthetic Communications, 39(10), 1801(2009), DOI: $10.1080 / 00397910802592874$

3. F.M. Moghaddam, H. Saeidiam, Z. Mirjafary, A. Sadeghi, Journal of Iranian Chemical Society, 6(2), 317 (2009), DOI:10.1007/BF03245840

4. M.H. Sarvari, S. Etmad, Tetrahedron, 64(23), 5519 (2008), DOI:10.1016/j.tet.2008.03.095

5. M. Wang, N. Zhao, W. Wei, Y. Sun, Industrial Engineering and Chemistry Research, 44(19), 7596 (2005), DOI: 10.1021/ie0504553

6. S. Ashoka, P. Chithaiah, K.V. Thipperudaiah, G.T. Chandrappa, Inorganica Chimica Acta, 363(13), 3442 (2010), DOI:10.1016/j.ica.2010.06.048

7. M.H. Sarvari, H. Sharghi, Journal of Organic Chemistry, 69(20), 6953 (2004), DOI:10.1021/jo0494477 
RASĀYAN J. Chem.

Vol. 13 | No. 1 |548 - 555| January - March | 2020

8. H. Thakuria, B. Borah, G. Das, Journal of Molecular Catalysis A: Chemical, 274(1-2), 1 (2007), DOI: 10.1016/j.molcata.2007.04.024

9. B.P. Bandgerd, P.E. More, V.T. Kamble, S.S. Sawant, Australian Journal of Chemistry, 61(12), 1006 (2009), DOI: $10.1071 / \mathrm{CH} 08202$

10. M.H. Sarvari, Journal of Iranian Chemical Society, 8(Suppl 1), 119 (2008), DOI: $10.1007 / \mathrm{BF} 03254288$

11. M.H. Sarvari, 2012, "Greener Solvent-Free Reactions on ZnO," In: Green ChemistryEnvironmentally Benign Approaches, Eds. M. Kidwai and N.K. Mishra, InTech Janeza Trdine, Rijeka, 103.

12. M.H. Sarvari, Synthetic Communications, 38(6), 832 (2008), DOI:10.1080/00397910701845274

13. R.M. Alwan, Q.A. Kadhim, K.M. Sahan, A. Ali, R.J. Mahdi, N.A. Kassim, A.N. Jassim, Nanoscience and Nanotechnology, 5(1), 1 (2015), DOI:10.5923/j.nn.20150501.01

14. S. Siva Kumar, P. Venkateswarlu, V. Ranga Rao, G. Nageswara Rao, International Nano Letters, 3, 30 (2013), DOI: 10.1186/2228-5326-3-30

15. R. Sadraei, Journal of Chemistry, 5, 45(2016)

16. M. Haritha, V. Meena, C.C. Seema, B. Srinivasa Rao, Rasayan Journal of Chemistry, 4(1), 217 (2011).

17. S. Ghosh, P-C. Chiang, J.L. Wahlstrom, H. Fujiwara, J.G. Selbo, S.L. Roberds, Basic \& Clinical Pharmacology \& Toxicology, 102(5), 453 (2008), DOI:10.1111/j.1742-7843.2008.00213x

18. B. Haseena Banu, K.V.S.R.G. Prasad, K. Bharathi, European Journal of Medicinal Chemistry, 78, 72 (2014), DOI:10.1016/j.ejmech.2014.03.037

19. B. Gabriele, G. Salerno, R. Mancuso, M. Costa, Journal of Organic Chemistry, 69(14), 4741 (2004), DOI: $10.1021 /$ jo0 494634

20. S.R. Mulla, C.V. Rode, A.A. Kelkar, S.P. Gupte, Journal of Molecular Catalysis A: Chemical, 122(2-3), 103 (1997), DOI:10.1016/S1381-1169(97)00023-X

21. J. Zhao, Z. Li, S. Yan, S. Xu, MA. Wang, B. Fu, Z. Zhang, Organic Letters, 18(8), 1736 (2016), DOI: $10.1021 /$ acs.orglett.6b00381

22. T. Sasada, F. Kobayashi, N. Sakai, T. Konakahara, Organic Letters, 11(10), 2161 (2009), DOI: $10.1021 / \mathrm{ol} 900382 \mathrm{j}$

23. M. Mane, R. Balaskar, S. Gavade, P. Pabrekar, D. Mane, Arabian Journal of Chemistry, 6(4), 423 (2013), DOI: 10.1016/j.arabjc.2011.01.030

24. E. Artuso, I. Degani, R. Forchi, C. Magistris, Synthesis, (22), 3497 (2007), DOI:10.1055/s-2007990813

25. S-H. Lee, H. Matsushita, B. Clapham, K.D. Janda, Tetrahedraon, 60(15), 3439 (2004), DOI: $10.1016 /$ j.tet.2004.02.034

26. K.J. Padiya, S. Gavade, B. Kardile, M. Tiwari, S. Bajare, M. Mane, V. Gavade, S. Varghese, D. Harel, S. Kkurhade, Organic Letters, 14(11), 2814 (2012), DOI:10.1021/ol301009d

27. J.A. Gryzb, M. Shen, C. Yoshina-Ishii, W. Chi, R.S. Brown, R.A. Batey, Tetrahedron, 61(30), 7153 (2005), DOI: 10.1016/j.tet.2005.05.056

28. P. Dube, N.F. Nathel, M. Vetelino, M. Couturier, C.L. Aboussafy, S. Pichette, M.L. Jorgensen, M. Hardink, Organic Letters, 11(24), 5622 (2009), DOI:10.1021/o19023387

29. G. Li, L.A. Hasvold, Z.F. Tao, G.T. Wang, S.L. Waltney, J. Patel, P. Kovar, R.B. Credo, Z. Chen, H. Zhang, Bioorganic and Medicinal Chemistry Letters, 16(8), 2293 (2006), DOI: $10.1016 /$ j.bmcl.2006.01.028

30. T.W. Greene, P.G.M. Wuts, Protective Groups in Organic Synthesis, Third Edition, John Wiley \& Sons Inc., 1999, DOI: 10.1002/0471220574

31. S. Batra, Z. Tusi, S. Madapa, Anti-Infective Agents in Medicinal Chemistry, 5(2), 135 (2006), DOI: $10.2174 / 187152106776359048$

32. A. Teimouri, N. Soltani, A.N. Chermahini, Frontiers in Chemical Science and Engineering, 5(1), 43 (2011), DOI: 10.1007/s11705-010-0532-7

33. R. Amjad, M.A. Munawar, S.R. Khan, M. Naeem, M. Sohaib, Journal of Chemical Society of Pakistan, 33, 107(2011). 
RASĀYAN J. Chem.

Vol. 13 | No. 1 |548 - 555| January - March | 2020

34. X-Q. Li, W-K. Wang, Y.X. Han, C. Zhang, Advanced Synthesis \& Catalysis, 352(14-15), 2588 (2010), DOI: $10.1002 /$ adsc.201000318

35. X-Y. Cao, J-C. Zheng, Y-X. Li, Z-C. Shu, X-L. Sun, B-Q. Wang, Y. Tang, Tetrahedron, 66(51), 9703 (2010), DOI: 10.1016/j.tet.2010.10.038

36. Z. Zhang, P.R. Schreiner, Chemical Society Reviews, 38(4), 1187 (2009), DOI:10.1039/ B801793J

37. A.F. Hegarty, L.J. Drennan in 'Comprehensive Organic Functional Group Transformations', Ed. A.R. Katrizky, O. Methocohn, C.W. Rees, Pergamon, Oxford, 6, 499 (1995).

38. A. Velavan, S. Sumathi, K.K. Balasubramanian, Organic \& Biomolecular Chemistry, 10(31), 6420 (2012), DOI: $10.1039 / \mathrm{C} 2 \mathrm{OB} 25412 \mathrm{C}$

39. H. Nakamura, H. Yamamoto, PCT Int. Appl. WO 2005043630 (2005), Chemical Abstracts, 142, 440277 (2005).

40. W. Mostafa, E. Elgazzar, G.W. Beall, S.S. Rashed, E.M. Rashad, International Journal of Applied Research, 290 (2018).

41. A. Alkahlout, N. Al Dahoudi, I. Grobelsek, M. Jilavi, PW. de Oliveira, Journal of Materials, 2014, (2014), DOI: $10.1155 / 2014 / 235638$

42. H. Peng, X. Liu, W. Tang, R. Ma, Scientific Reports, 7, 2250 (2017), DOI:10.1038/s41598-01702501-w

43. P. Bindu, S. Thomas, Acta Physica Polonica A, 131(6), 1474(2017), DOI: 10.12693/APhysPolA.131.1474

44. A. Raj, L. Reena, Rasayan Journal of Chemistry, 11(3), 1339(2018), DOI: 10.31788 /RJC.2018.1132009

45. A. Kiruthiga, R. Kannan, T. Krishnakumar, Rasayan Journal of Chemistry, 11(1), 18 (2018), DOI: 10.7324/RJC.2018.1111935

46. A.K. Zaka, W.H. Abd, M.M. Darroudi, R. Yousefi, Material Letters, 65(1), 70(2011), DOI: 10.1016/j.matlet.2010.09.029

47. R.Y. Hong, J.H. Li, L.L. Chen, D.Q. Liu, H.Z. Li, Y. Zheng, J. Ding, Powder Technology, 189(3), 426 (2009), DOI:10.1016/j.powtec.2008.07.004

48. P. Sakthivel, A.C. Fernandez, J. Jesudbahrurai, Elixir Nanocomposite Materials, 50, 10558 (2012).

49. M-k Leung, J-L Lai, K-H Lau, H-h Yu, H-J Hsiao, Journal of Organic Chemistry, 61(12), 4175 (1996), DOI: 10.1021/jo9522825

50. H. Wang, J. Dongyuan, T. Jianwei, G. Yonghong, Preparation of N, N'-dicyclohexylurea. CN101279932A, (2008).

[RJC-5487/2019] 